\title{
New alternative test for Mycobacterium tuberculosis complex
}

Novo teste alternativo para o complexo Mycobacterium tuberculosis

\section{To the Editor:}

1 read the report on the alternative test for the presumptive identification of Mycobacterium tuberculosis complex with a great interest. ${ }^{(1)}$. Simeão et al. recommended "the combined screening test to rapidly identify $M$. tuberculosis in resource-poor settings and in less well-equipped laboratories while awaiting definite identification by molecular or biochemical methods."(1) 1 agree that the new alternative test might be effective in the diagnosis. However, there are some concerns. First, this technique depends on the level of expertise of the clinical microscopist, hence the diagnostic yield will vary in different settings. Determining standards for clinical microscopy is a common problem in laboratory medicine, and there is as yet no international consensus. Second, the cost analysis in this report is only a cost identification and does not focus on the outcome. A cost- effectiveness or cost-utility analysis should have been presented. Third, it remains questionable whether there will be any experienced clinical microscopists available to perform the test in settings in which the laboratories are less wellequipped.

Viroj Wiwanitkit

Professor of Tropical Medicine, Visiting

Professor, Hainan Medical College, China

\section{References}

1. Simeão FC, Chimara E, Oliveira RS, Yamauchi JU, Latrilha FO, Telles MA. Cord factor detection and macroscopic evaluation of mycobacterial colonies: an efficient combined screening test for the presumptive identification of Mycobacterium tuberculosis complex on solid media. J Bras Pneumol. 2009;35(12):1212-6. 